\title{
ON THE CRIMINALISTIC STUDY OF UNCONVENTIONAL FIREARMS
}

\section{Melnyk R. .}

The article deals with the peculiarities of the study into unconventional firearms as well as the accompanying problems and the ways to solve them. Insufficient availability of training and reference materials on this topic creates a number of obstacles for forensic experts in their practice. The situation is also complicated by the limited access of specialists to specialized publications, along with outdated sources or absence of any sources on the subject. Investigation and expert practice deal with many types of firearms that differ from standard issues by the way of production, construction properties, technical and ballistic specifications. Criminalistic and legal sources use various names that differ from the names officially assigned to those firearms and differ by constitutional properties peculiar to certain groups of weapons. Because of this terminological confusion criminalists do not have a unified position regarding the objects to be studied, i.e. they face difficulties in deciding the question of classifying an item with a particular type or subtype of firearms.

Keywords: self-made, altered firearms, altered starting both gas pistols and revolvers, self-made barrel, partition or plug removal, cartridges.

А. Н. Герман, заведующий лабораторией Харьковского НИИСЭ

\section{ОСОБЕННОСТИ ИДЕНТИФИКАЦИОННЫХ ИССЛЕДОВАНИЙ ПРИ УСТАНОВЛЕНИИ ПРИНАДЛЕЖНОСТИ К ОДНОМУ ПАТРОНУ ВЫСТРЕЛЯННЫХ ПУЛИ И ГИЛЬЗЫ КАЛИБРА 7,62×39}

На основе результатов экспериментальных исследований установлена специфика механизма образования следов взаимодействия на наружных поверхностях пуль и внутренних поверхностях дульиев гильз промежуточных патронов калибра 7,62×39. Выявлены особенности проведения идентификационных исследований при установлении принадлежности пули и гильзы к одному промежуточному патрону указанного калибра, а также предложен специальный экспериментальныий снаряд для воспроизведения следов от дульиа гильзы.

Ключевые слова: внутренняя поверхность дульиа гильзы, идентификационные исследования, наружная поверхность пули, микрорельеф, обжим дульиа гильзы, следы взаимодействия, специальный снаряд, сплав Вуда.

В практике судебной баллистики идентификационные исследования по установлению принадлежности к одному патрону выстрелянных пуль и гильз относятся к категории сложных, что обусловлено спецификой механизма

(C) Герман А. Н., 2015 
образования следов взаимодействия на поверхностях ведущих частей пуль и на внутренних поверхностях дульцев гильз, а также существенным негативным влиянием на их характер внешних факторов, имеющих место в процессе производства выстрела.

Крепление пуль в гильзах промежуточных патронов калибра 7,62×39 осуществляется с помощью тугой посадки пули в дульце гильзы с последующим сегментным обжатием кромки дульца гильзы (рис. 1). В отдельных случаях, в охотничьих патронах зарубежного производства, при их снаряжении тяжелыми пулями, крепление осуществляется только с помощью тугой посадки (рис. 2, 3).

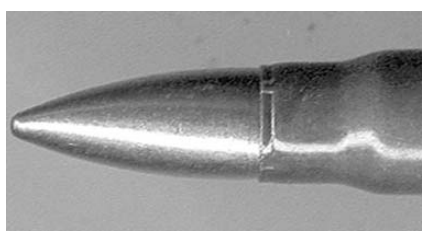

Рис. 1. Характер крепления пули в гильзе боевого промежуточного патрона калибра 7,62×39

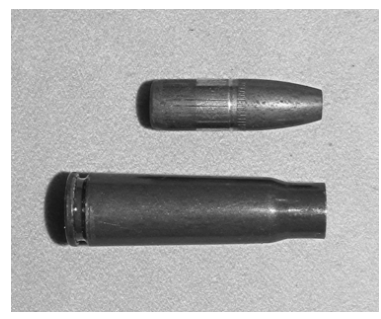

Pис. 2. Экспансивная пуля и гильза охотничьего патрона калибра 7,62×39 венгерского производства

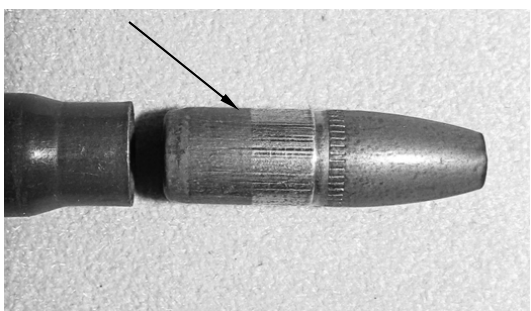

Рис. 3. Характер следов взаимодействия (указаны стрелкой) на поверхности ведущей части пули охотничьего патрона калибра 7,62×39 венгерского производства

В процессе снаряжения патронов пули помещаются в дульце гильз с некоторым натягом, что обусловливает достаточно плотный контакт между поверхностью ведущей части пули и соответствующего участка внутренней поверхности дульца гильзы.

При посадке пуль вглубь дульца из-за незначительных отклонений геометрических параметров и состояния кромки дульца гильз образуются линейные трассы, которые параллельны продольной оси. Это первичные динамические следы взаимодействия между поверхностями пули и дульца гильзы. В процессе выстрела, в его начальный период, когда под действием давления форсирования пуля страгивается с места и начинает 
поступательное движение вперед, при отсутствии дополнительного сегментного обжима кромки дульца гильзы, указанные первичные следы остаются практически неизменными (рис. 3). Они имеют линейную форму, могут быть сплошными (равномерно распределенными по всей боковой поверхности пули) либо отображаться отдельными группами. Как правило, линия начала следов сопрягается с нижней границей канелюры на пуле, линия окончания следов сопрягается с границей сужающейся хвостовой части пули.

На внутренней поверхности дульца гильзы также образуются следы взаимодействия в виде трасс линейной формы с различной плотностью распределения (рис. 4).

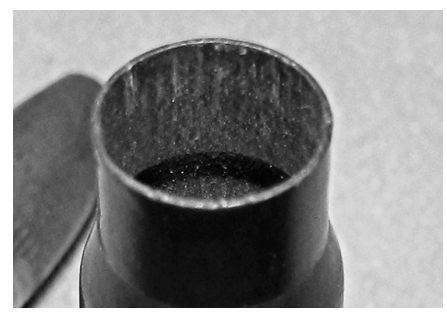

Рис. 4. Характер следов взаимодействия на внутренней поверхности дульца гильзы

Крепление пуль в гильзах охотничьих промежуточных патронов калибра 7,62×39 с помощью только натяга имеет ограниченное применение. В подавляющем большинстве крепление пуль в боевых и спортивно-охотничьих патронах указанного калибра осуществляется с помощью плотного натяга и дополнительного сегментного обжима кромки дульца гильзы, что существенно повышает значение извлекающего пулю усилия и ведет к росту давления форсирования и стабилизации внутрибаллистических параметров процесса выстрела.

Наличие участков сегментного обжима кромки дульца гильзы приводит к существенному видоизменению микрорельефа в первичных следах взаимодействия, образующихся в процессе снаряжения пули в дульце гильзы. Загнутые вовнутрь участки дульца гильзы при поступательном движении пули вперед практически полностью перекрывают первичные следы взаимодействия и образуют свой характерный микрорельеф в виде трасс линейной формы. Они сгруппированы на участках поверхности ведущей части пули, которые по своим параметрам соответствуют границам и размерам сегментных выступов на внутренней поверхности кромки дульца гильзы.

Следует отметить, что размеры и форма этих выступов при проведении идентификационных исследований могут быть отнесены к общим признакам. В дальнейшем, по мере продвижения пули вперед в канале ствола, на 
ней от нарезов последовательно образуются первичные и вторичные следы канала ствола. Они занимают достаточно большую площадь ведущей поверхности пули, что приводит к перекрытию ими следов взаимодействия пули с дульцем гильзы.

Сохранившиеся следы взаимодействия пули и дульца гильзы также могут быть перекрыты следами контакта пули с преградой (преградами). Как правило, при попадании пули в преграду происходит ее деформация и образуются множественные следы контакта различной формы, протяженности и степени выраженности.

В большинстве случаев указанные факторы приводят к невозможности проведения идентификационных исследований с целью установления принадлежности одному патрону выстрелянных пули и гильзы, что обусловлено недостаточным количественным набором трасс ${ }^{1}$, а также незначительной их протяженностью и устойчивостью.

Тем не менее, при сохранении участков со следами взаимодействия на поверхности пули, проведение соответствующих идентификационных исследований возможно. Основной проблемой в этих исследованиях является получение экспериментальных следов, необходимых для установления тождества сравниваемых объектов. Непосредственное сравнение следов на внутренней поверхности дульца гильзы и наружной поверхности пули невозможно.

Для получения экспериментальных следов предлагается использовать специальный снаряд цилиндрической формы с центральным сквозным каналом. Снаряд, изготовленный из сплава Вуда либо из сплавов на основе свинца, олова, должен иметь гладкую поверхность и свободно (с незначительным зазором) входить в дульце исследуемой гильзы. Перед началом проведения экспериментальных исследований в канал снаряда помещается стержневой дорн со сферическим утолщением. После установки снаряда с дорном в дульце гильзы последний извлекается из снаряда. Благодаря утолщению, по мере прохождения дорн деформирует стенки снаряда, вследствие чего достигается плотный контакт между внешней поверхностью экспериментального снаряда и внутренней поверхностью дульца гильзы.

Извлечение экспериментального снаряда может быть осуществлено с помощью инерциального молотка, который в практике судебно-баллистической экспертизы используется для демонтажа патронов. Благодаря инерциальным перегрузкам экспериментальный снаряд свободно выходит из дульца гильзы и на его поверхности воспроизводятся следы взаимодействия, которые могут быть успешно использованы для последующих идентификационных исследований (рис. 5).

1 См.: Грановский Г. Л. Вероятностная оценка пригодности линейных (динамических) следов для идентификации : методические рекомендации для экспертов / Г. Л. Грановский. - М. : ВНИИСЭ, 1985. - 20 с. 


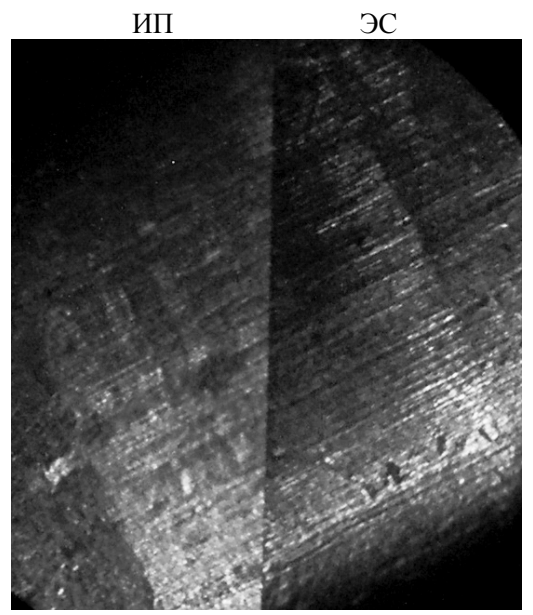

Рис. 5. Совмещение микрорельефа в следах взаимодействия на поверхностях исследуемой пули (ИП) и экспериментального снаряда (ЭС)

Таким образом, исследование механизма образования следов взаимодействия между пулей и гильзой промежуточного патрона калибра 7,62×39 в процессе его снаряжения и факторов, которые оказывают негативное влияние на характер этих следов, свидетельствует о том, что при наличии сохранившихся участков с достаточным количеством пригодных трасс, указанные следы могут быть использованы для идентификационных исследований по установлению принадлежности одному патрону выстрелянных пули и гильзы. При этом разработанный экспериментальный снаряд, позволяющий воспроизвести следы дульца гильзы, может быть эффективно использован для всех гильз бутылочной формы иных калибров. Кроме того, предложенный метод получения экспериментальных следов достаточно прост и не требует высокотехнологичного специализированного оборудования, что позволяет сократить сроки проведения исследований.

\section{ОСОБЛИВОСТІ ІДЕНТИФІКАЦЙНИХ ДОСЛІДЖЕНЬ ПРИ ВСТАНОВЛЕННІ НАЛЕЖНОСТІ ДО ОДНОГО ПАТРОНА ВИСТРІЛЯНИХ КУЛІ ТА ГІЛЬЗИ КАЛІБРУ 7,62×39}

\section{Герман О. М.}

На основі результатів експериментальних досліджень установлено специфіку механізму утворення слідів взаємодії на зовнішніх поверхнях куль і внутрішніх поверхнях дульців гільз проміжних патронів калібру 7,62×39. Виявлено особливості проведення ідентифікаиійних досліджень при встановленні приналежності кулі й гільзи до одного проміжного патрона зазначеного калібру, а також запропоновано спеціальний експериментальний снаряд для відтворення слідів від дульияя гільзи. 
Ключові слова: внутрішня поверхня дульия гільзи, ідентифікаиійні дослідження, зовнішня поверхня кулі, мікрорельєф, обтиск дульия гільзи, сліди взаємодії, спеціальне знаряддя, сплав Вуда.

\section{PECULIARITIES OF IDENTIFICATION STUDIES INTO WHETHER A FIRED 7.62×39 CALIBER BULLET AND CASE BELONG TO THE SAME CARTIDGE}

\section{German A. N.}

Based on experimental research, the article determines the peculiarities of the impact trace formation mechanism on the external surfaces of the bullet and on the internal surfaces of the case mouths in $7.62 \times 39$ caliber intermediate cartridges. The article determines the influence of the case mouth crimp on the properties of the abovementioned traces, it also provides peculiarities of undertaking identification studies to establish whether the bullet and case belong to the same cartridge of the given caliber. It suggests using a special shell to reproduce experimental interaction traces and the way of its application, it allowed to obtain a solid identifiable microrelief on the surfaces of experimental samples. The article suggests the most suitable material for this type of a shell capable of reproducing traces. This kind of studies do not require special equipment and involvement of highly qualified specialists, experiments are prepared and conducted only with the use of available resources and common equipment. The suggested method can be applied for relevant traceological studies of material objects with curved contact surfaces that interacted with each other.

Keywords: internal surface of the case mouth, identification studies, external surfaces of the bullet, microrelief, case mouth crimp, interaction traces, special shell, Wood's alloy. 